\title{
KARANG PAUMAHAN PERSPEKTIF EKOLOGI HINDU
}

Oleh :

Hari Harsananda

Anak Agung Ayu Alit Widyawati

\begin{abstract}
Human needs a good home and yard as a primary necessary. A long Ago, before human know the food producting method, human have habit to be a nomaden, haven't home and always stay at the edge of the river, but with a good progression of our culture. Human start to stay and make a settlement. To make a good settlement Balinese people have a rule basic from a text called Asta Bhumi. From the the Asta Bhumi text can get the differentitation about the land, the good land and the bad land for make a Building. The example of the good land is the land who higher at the South and West, it called Paribhoga Werddhi and Manemu Labha, beside the rule about making ak settlement, Balinese people have a text to decreasing a bad factor from a good land. The text called Bhama Kretih, at the Bhama kretih text, find a method to solve bad land problem uses Upakara called Caru.
\end{abstract}

Key Word : Karang Paumahan, Asta Bhumi, Bhama Kretih

\section{PENDAHULUAN}

Manusia pernah hadir selaku kelompok individu yang hidup secara nomaden, kondisi ini seiring sejalan dengan peradaban manusia yang masih dalam pola food gathering atau pola konsumsi dengan mengandalkan pola - pola berburu. Perkembangan kebudayaan manusia yang mulai beralih dari food gathering menuju food producting menjadikan menjadikan pola kehidupan manusia pada aspek pola tinggal juga berubah, jika sebelumnya pola tinggal manusia menggunakan sistem nomaden atau berpindah-pindah tergantung SDA pada suatu tempat, kini dengan adanya pola memproduksi makanan, pola tinggal manusia berubah menjadi pola tinggal menetap pada suatu wilayah yang sifatnya tetap.
Walaupun sudah hidup dengan pola menetap,namunpadamasadahulu,pembangunan wilayah pemukiman masih didasari pada kondisi geologis yang mendukung penuh aktivitas food producting sehingga sangat wajar, temuan - temuan benda purbakala memiliki kecenderungan ditemukan di sepanjang aliran sungai disebabkan, pola permukiman penduduk kala itu memang memiiki kecenderungan untuk berada di wilayah sepanjang aliran sungai. Hal ini menjadi alasan logis banyak peradaban hebat di masa lalu berdiri dekat dengan aliran sungai, contohnya saja perdaba mesir dan peradaban sungai Sindhu. 
Semenjak dahulu, rumah atau pemukiman memang menjadi suatu hal yang essensial dimiliki oleh manusia selain makanan dan pakaian, sehingga istilah "papan" yang merupakan representasi dari pemukiman sendiri juga masuk ke dalam kebutuhan primer atau kebutuhan utama yang wajib dipenuhi oleh manusia. Maslow dalam teori The Hierarchy of Needs juga merumuskan bahwa rumah adalah salah satu kebutuhan yang wajib dimiliki oleh manusia. Lebih lanjut lagi menurut Maslow dalam Iskandar (2016:27) posisi pemukiman atau tempat tinggal merupakan bagian dari kebutuhan fase kedua atau pemenuhan akan rasa aman, hal itu di dasari pada fungsi rumah sebagai bangunan yang yangfungsinya melindungi manusia manusia dari iklim, cuaca,biantang buas dll.

Berdasarkan pada realitas tersebut, tidak mengherankan masyarakat umum selalu memiliki banyak pertimbangan dalam rangkaian pembangunan sebuah rumah, baik dari sisi luas tanah, luas bangunan letak yang representative serta kondisi niskala niskala yang juga menjadi bahan pertimbangan. Banyak sekali metode yang berkembang dalam usaha menakar baik -buruknya suatu kondisi rumah, salah satu yang terkenal adalah budaya feng shui milik masyarakat China yang sudah memetakan tata letak bangunan guna mendapat keberuntungan dan kesehatan. Hindu sendiri juga senyatanya memilikinya, dalm proses pembangunan rumah , banyak faktor yang sudah mulai diperhitungkan mulai dari karang atau tanah, sikut atau ukuran serta langkah -langkah yang harus diambil sebelum membangun sebuah rumah. Pada bagian berikutnya akan dibahas mengenai hal hal tersebut.

\section{Karang Paumahan dalam Hindu}

\subsection{Hala Hayuning Palemahan}

Konsep Karang Paumahan secara harfiah dapat diartikan sebagai sebuah kesatuan antara halaman dan bangunan. Kedua aspek ini dalam keyakinan masyarakat Hindu memiliki singkronisasi satu dengan lainnya sehingga kondisi yang ideal bagi keduanya diperlukan dalam menghasilkan situasi rumah yang baik, dan kondusif baik secara sakala maupun niskala. Maka dari itu, sebelum membangun rumah, maka pemilihan tanah selaku palemahan juga menjadi langkah awal yang harus dilakukan. Adapun Hala -Hayuning Palemahan atau baik buruknya tanah menurut beberapa sumber adalah sebagai berikut :

\section{a) Hayuning Palemahan}

\section{Ring Pascima Manemu Labha}

Yening wenten sinalih tunggil palemahan sada menggik kauh, semalih ipun pagenahannya tinggar, punika kebaos karang sane "manemu labha"

Artinya : Jika ada tanah yang lebih tinggi pada bagian baratnya maka tanah tersebut baik dan disebut tanah yang menemukan keberuntungan.

\section{Ring Daksina Paribhoga wredhi} Yening palemahan menggik kelod, lebah kaler kawastanin Paribhoga Wredhi utawi wredhi putra, artin ipun tan pundit pangan kinum sang ngumahin, 
Artinya : jika tanah lebih tinggi pada bagian selatannya dan rendah pada bagian utaranya dinamakan paribhoga wredhi atau wredhi putra yang artinya yang tinggal di tanah tersebut tidak akan kekurangan pangan.

3. palemahan asah : madya

Palemahan sane asah, tan katawengan saking nyatur desa mekadi ring penyandingya tan wenten sane menggik gumanti naonin puniki kabawos " Madya” sane kabawos wiadin mapiteges tan wenten bas becik lan bas kawon

Artinya : tanah yang datar dan tidak ada yang tinggi maupu rendah dibanding areal sekitarnya disebut sebagai tanah yang "Madya" atau bisa disebut tanah yang tidak terlalu bagus maupun tidak terlalu jelek ( sedang - sedang )

4. Palemahan Hinang : Dewa Ngukuhi Wenten palemahan, yadyan menggik,asah,siong utawi lebah nanging yan paspadayang tur rasayang, tandugi mawa kliyab sane demdem, renteb tur hinang, jantos ngawetuang kakleteg kahyune asri ring sang ngranjing irika.Palemahan sane sane asapunika kawentenan ipun, kabawos "Dewa Ngukuhi” sane mateges jeneking Para Hyang.

Artinya: ada tanah yang walaupun tinggi, datar maupun rendah tetapi jika kita berada disana merasa tenang serta menjadikan perasaan asri ketika memasukinya, tanah yang demikian yang disebut “ Dewa Ngukuhi” yang artinya di naungi oleh para Dewa ( Suandra, 1990: 1-2 )

\section{b) Halaning Palemahan}

Selain Hayuning pekarangan atau Palemahan ada pula Halaning pekaranga yaitu pekarangan atau tanah yang kurang baik posisinya sehingga sebaiknya di hindari untuk di bangun atau jika sudah terlanjur terbangun rumah, ada solusi yang dilakukan untuk menghindari efek buruk dari pekarangan yang kurang baik tersebut adapun jenis karang nyakitin atau halaning palemahan adalah sebagai berikut :

1. Karang Sandang Lawe :

Tanah atau pekarangan yang letaknya tepat berhadap - hadapan diantara sisi jalan atau gang. Dimiliki oleh satu orang atau satu keluarga purusa (garis keturunan lelaki). Karang dengan kondisi demikian disebut karang sandang lawang

2. Karang Tledu Nginyah

Tanah atau pekarangan dalam satu garis purusa yang letaknya berseberangan jalan atau gang, dengan sudut tanah yang saling berhadapan satu engan lainnya

\section{Karang Ngulonin}

Pekarangan atau tanah dan rumah tinggal yang letaknya berdampingan dengan Balai banjar atau Pura dengan posisi berada di hulu ( timur atau utara) dari Bale Banjar atau Pura tersebut. 


\section{Karang manyeleking}

Tanah atau pekarangan yang terdapat dua sanggah Sasuhunan di dalamnya namun berbeda Lelintihan atau garis keturunan. Selain kondisi di atas karang manyeleking juga bisa dalam kondisi dalam satu pekarangan terdapat dua keluarga dengan lelintihan atau garis keturunan yang berbeda contohnya dalam satu pekarangan, terdapat dua warga, warga Pasek dan Brahmana.

\section{Karang Kalingkuhan}

Tanah atau pekarangan yang letakya berada pada sudut pekarangan orang lain atau terdapat pekarangan orang lain yang mengitari pekarangan sendiri.

\section{Karang Kuta kubandha}

Tanah atau pekarangan yang letak atau posisinya dikelilingi oleh jalan, gang atau got

(jelinjing)

\section{Karang Sandang lawe}

Tanah atau pekarangan yang letak atau posisinya diapit oleh tanah atau pekarangan yang dimiliki oleh satu garis katurunan kapurusan.

\section{Karang Sulanupi}

Tanah atau pekarangan yang letaknya berada pada sudut pertigaan jalan tau gang, atau setengah dari sisi tanah pekarangan dilingkari oleh jalan, gang, got dan sungai atau tukad.
9. Karang Suduk Angga

Tanah atau pekarangan yang letak atau posisinya tertusuk (katumbak) jalan, gang,dan sungai

\section{Karang Catuspata}

Tanah atau pekarangan yang terletak pada susut perempatan jalan atau gang. Kondisi tanah yang demikian sama nilainya dengan tanah pekarangan yang terletak di sebelah kuburan /setra.karang seperti ini termasuk karang panes, karang nyakitin karena perempatan atau Catus Pata berstatus sebagai sthana Sang Hyang Panca Durga

Kesepuluh jenis letak pekarangan di atas dikatakan sebagai karang nyakitin dan karang panes, karang demikian dapat menimbulkan beragam dampak buruk bagi orang yang menempati areal tanah atau pekarangan tersebut antara lain : sering terkena musibah,sering terjadi kesalah pahaman, sakit - sakitan, sulit mendapatkan keturunan,sering diganggu makhluk halus (Wijayananda, 2004: 27).

Adapun solusi dari masing masing kondisi halaning Palemahan di atas berdasarkan Teks Bhama Kretih adalah sebagai berikut :

1. Karang Tledu Nginyah : Untuk menetralisir pengaruh - pengaruh yang tidak baik maka langkah yang dapat diambil adalah dengan jalan merelakan tanah atau pekarangan untuk diundur tembok penyengkernya agar sudut tanah atau pekarangannya tidak lagi berhadap - hadapan dengan tanah pekarangan 
yang di seberang serta ditambah upacara Pamahayu Karang.

2. Karang Kalingkuhan: Untuk mentralisir tanah kalingkuhan tanah tersebut agar dibuatkan upacara pecaruan pemahayu pekarangan, kemudian di luar tembok pekarangan atau di samping pintu masuk pekarangan dibangun palinggih Padmacapa,sebagai sthana Sang Hyang Indrablaka, dan Sang Hyang Kalamaya.

3. Karang Sulanupi : Untuk mentralisir dampak negatif dari pekarangan ini hendaknya pekarangannya dibuatkan upacara pecaruan pamahayu karang dengan caru Jigramaya dan di luar tembok pekarangan pada areal sudutnya yang berhadapan langsung dengan pertigaan jalan dibangun Palinggih Padmacap.

4. Karang Catuspata : untuk mengatasi karang panes ini hampir sama dengan cara mengatasi kasus karang Sulanupi yaitu dengan melaksanakan upacara pecaruan pemahayu karang dan membangun palinggih Padma capah sebagi sthana Sang Hyang Idrablaka dan Sang Hyang Durgamaya.

5. Karang Suduk Angga :Hampir mirip dengan solusi di atas, hanya saja posisi membangun Padma Capah harus tepat berada secara berhadapan dengan jalan yang menusuknya ( numbak)

6. Karang Sandang lawang : kondisi tanah dan pekarangan seperti ini belum ditemukan solusi dalam bentuk upacaranya dalam sumber sastra, sehingga solusi yang terbaik adalah degan merelakan salah satu tanah untuk di jual agar tidak dimiliki oleh satu garis Kapurusan

7. Karang Manyeleking : Untuk kondisi Karang Manyeleking juga belum ditemukan solusi dari sisi upacara, sehingga solusinya adalah salah satu dari keluarga yang bertempat di pekarangan tersebut harus pindah sehingga dalam pekarangan hanya di tempati oleh satu garis Lelintihan

8. Karang Sandang Lawe : Untuk Kondisi pekarangan Sandang Lawe solusi satu satunya adalah dengan pindah tempat tinggal karena belum ditemukan sarana Pamarisudha nya ( Suhardana, 2009:10)

Teks Bhama Kretih merumuskan bahwa paling tidak ada dua jenis upakara yang dapat di gunakan sebagai penawar bagi kondisi karang panes seperti jenis - jenis pekarangan di atas yaitu caru Pamahayu karang dan caru Jigramaya adapun kompone dari masing masing caru tersebut adalah sebagai berikut :

1. Caru pamahayu karang / pengasih Bhuta:

Sarana : Sasenden anyar masurat surya lan candra, medaging tumpeng putih asiki, tumpeng kuni asiki, iderin antuk sarwa sekar, rakan nyane putih kuning, iwak ayam suddhamala pinanggang, bebek putih maguling, canang genten. Sawusan pinuja pendhem ring tengahing natar pekarangan. Phalanya Dewa teka asih, Bhuta teka asih. 
Pujanya : Om, Indah Ta Kita Bhatari Durga, dening kita hanuduh I Bhuta mangsa, apan kita wus sinungan sajin nira. Om, Indah ta kita hangken sapenagkan ta paran-paranya, haywa ta kita hanglarani hangrubheda manusan nira, iki tadhah sajin nira, wus ta sira padha hanadhah saji, mundura ta sira maring pasenetan nira, kemiten manusan nira, siddha amagguhang dirghayusa paripurna.

Om Sidhdhir astu ya namah.

\section{Caru Jigramaya}

Sarana : caru ayam putih mulus maolah dadi 5 tanding, malayang, layang majejantah lembat asem padha makatih, urab barak, urab putih, tempengnya padha madanan, olahannya padha winadhahan sengkwi, sawusan pinuja, caru punika pendhem ring bilang bucuning pekarangan, laying -layang nyane pendhem ring tengah natar pekarangan nyane.

Pujanya: Ih, Kita Snag Bhuta Jigramaya, marupa manca warna, kita retuning Bhuta kala Dhengen, makanak I Pamali Pulung raksa, I undar - andir, ekadasa rowing nira, kita anggawe kepanjingan Hyang lalah, kesandering glap, katiben amuk, kasiratin rah, salwiring cuntaka bhayaning pekarangan, kalebur kapunah de nira sang Bhuta jigramangsa. Om, Ang Ksama sampurna ya namah Swaha.
Penentuan pintu keluar dari sebuah pekarangan merupakan hal yang penting disebabkandalam tata urutanmembangun rumah, menurut teks asta kosala-kosali dan asta bhumi prose nyikut Panyengker (mengukur tembok) adalah proses kedua setelah proses pemilihan tanah dan proses upacara Pengeruwakan karang.menurut Wijayananda (2004:39) untuk membuat pintu masuk atau keluar tidak boleh sembarangan, karena pintu masuk merupakan sthana dari Sang Hyang Dorakala, yang secara etimologi kata, Dora artinya pintu (Lawang) dan kala yang artinya waktu atau hari sehingga pintu berpengaruh terhadap kehidupan sehari hari bagi penghuninya.

Menurut teks Asta Bhumi dalam Pulasari (2008:34) proses mengukur atau nyikut pamedalan di awali dengan melantunkan mantra "Om Eka Dwaja Yo Nikretah" lalu membentangkan seutas tali sepanjang lokasi lahan yag akan di bangun lalu dibagi Sembilan ruas. Tiap tiap ruas memiliki nilai baik atau buruk, sehingga pemilihan ruas yang tepat sangat diperlukan untuk menciptakan Pamedalan yang bernilai baik, serta tiap arah dari calon pamedalan juga berbeda nilai dan arah menghitungnya.

Berikut akan di ulas secara lebih mendetail.

a. Pamedalan Kangin ( pintu keluar berada di timur )

Tata cara Nyikut Pamedalan yang berada di arah timur adalah dengan mulai mengukur panjang pekarangan dari arah utara ke selatan lalu membaginya menjadi Sembilan ruas. Kemudian nilai dari tiap - tiap ruasnya adalah sebagai berikut :

\section{Perih (buruk)}


2. Kinabhakten ( Baik)

3. Wreddhi Guna ( Baik)

4. Dhana Teka ( Baik)

5. Kabrahmanan ( Baik)

6. Dhana Wreddhi( Baik)

7.Nohan ( buruk)

8. Setri Jahat (buruk)

9. Cendek Tuwuh (buruk)

Berdasarkan hitungan di atas maka untuk membangun Pamedalan disebelah timur maka yang baik adalah pada ruas ke 2,3,4,5,6 dan hindari membangun pamedalan pada ruas ke 1,7,8, dan 9 .

b. Pamedalan kelod (pintu keluar di sebelah selatan)

Untuk Pamedalan kelod tatacaranya sama seperti di atas, namun mengukur dan membagi ruas panjang pekarangan dimulai dari arat timu ke barat. Kemudian nilai dari tiap - tiap ruasnya adalah sebagai berikut :

1. Bhaya Agung ( Buruk)

2. Tanpa Anak ( buruk)

3. Sukha Mageng ( baik )

4. Brahma Sthana (baik)

5. Dewa Wreddhi ( baik)

6. Sugih Rendah (baik)

7. teka Wreddhi (baik)

8. Kepaten ( buruk )

9. Kageringan (buruk)

c. Pamedalan Kauh ( pintu keluar di sebelah barat)
Untuk pamedalan kauh proses mengukurnya dimulai dari arah utara menuju selatan dengan rincian sebagai berikut :

1. Bhaya Agung ( Buruk)

2. Musuh Makweh ( Buruk)

3. Wreddhi Mas ( Baik)

4. Wreddhi Guna ( Baik)

5. Dhanawan ( Baik)

6. Brahma Sthana ( Baik)

7. Kinabhakten ( Baik)

8. Kapiutang (Buruk)

9. Karogha Kala ( Buruk)

d. Pamedalan Kaja ( Pintu keluar berada diarah utara)

Untuk Pamedalan Kaja proses pengukurannya dimulai dari arah timur menuju barat dengan rincian sebagai berikut :

1.Tanpa Anak ( Buruk)

2. Wikara ( Buruk )

3. Nohan (Buruk)

4. Kedalih ( Buruk)

5. Brahma Sthana ( Baik )

6. Piutangan (Buruk)

7. Sukha Mageng ( Baik )

8. Kawisesan ( Baik)

9. Kawighan (Buruk)

Uraian di atas menggambarkan bahwa ada dampak buruk dari pemilihan areal Pamedalan yang salah, tidak hanya sepele namun dapat menimbulkan kematian, tidak memiliki anak, sakit -sakitan dan sebagainya, sehingga tatacara Nyikut ini selaykanya mampu dipelajar dan 
diamalkan oleh setiap warga Hindu demi terciptanya lingkungan yang bagus, baik sekala maupun niskala.

\section{Simpulan}

Karang Paumahan merupakan salah satu kebutuhan primer bagi manusia, bahkan menurut Maslow, rumah diperlukan oleh manusia sebagai instrumen dalam memenuhi kebutuhan akan rasa aman. Senada dengan pendapat Maslow, dalam teks local Bali yaitu Asta Bhumi juga memuat tentang tatacara memilih pekarangan serta mengatur letak pekarangan sehingga terhindar dari nasib buruk atas letak pekarangan yang salah. Termuat juga dalam teks Bhama Kertih tentang sarana upakara yang dapat digunakan untuk menetralisir dampak negative dari suatu pekarangan jika seandainya sudah terlanjur memiliki pekarangan yang kurang baik. Selain pekarangan terdapat pula tatacara menentukan letak Pamedal atau pintu keluar dari sebuah rumah sesuai dengan letak arah mata anginnya, dengan metode ini diharapkan tercipta pekarangan rumah yang benar benar bagus, baik secara sekala, Maupun Niskala.

\section{Daftar Pustaka}

Iskandar. 2016. Implementasi Teori Hirarki Kebutuhan Abraham Maslow Terhadap Peningkatan Kinerja Pustakawan. Jurnal Khizanah Al-Hikmah vol. 4 no. 1, januari - juni 2016

Suhardana. Drs. K.M.2009. Bhama Kretih Penyucian Pekarangan panes, berbagai caru dan sarananya. Surabaya: Paramita
Kosala-kosali lan Asta Bhumi. Surabaya: Paramita

Suandra, I Made. 1990. Tuntunan/tatacara Ngwangun Karang Paumahan Manut Smrti Agama Hindu. Pemprov. Bali

Wijayananda, Ida Pandita Mpu.2004. Tata Letak Tanah dan Bangunan Pengaruhnya terhadap penghuninya

Pulasari. Jro Mangku.2008. Cakepan Asta 